\title{
Content Maps Help Low Spatial Capacity Users Memorize Link Structures in Hypertext
}

\author{
Zsófia Vörös ${ }^{*}$, , Jean-François Rouet ${ }^{2}$ and Csaba Pléh ${ }^{3}$ \\ ${ }^{1}$ Budapest University of Technology and Economics (BME), Hungary \\ ${ }^{2}$ CNRS and University of Poitiers, Centre de Recherches sur la Cognition et l'Apprentissage, 99 avenue du Recteur \\ Pineau, 86000 Poitiers, Hungary \\ ${ }^{3}$ BME, Department of Cognitive Science, Sztoczek u. 2, 1111 Budapest, Hungary
}

\begin{abstract}
We investigated the effect of spatial memory capacity and content maps on readers' memory for hypertext structure. Simple hierarchical hypertexts were built on four topics. For each topic there was a 6-node and a 9-node version. Each version came with or without a content map. Young adult participants were asked to read each hypertext with the purpose of learning the contents and structure. Then, they had to recall the layout of nodes and links. Memory for links varied as a function of spatial memory and the presence or absence of a map. When no map was available, high spatial memory participants drew more accurate maps than low memory participants. When a map was available the two groups had better results and did not differ from each other. The benefit of the map was larger for 9-node than for 6-node items. The results indicate that mentally representing hypertext structure relies on spatial working memory. Global content representations act as scaffolds for low spatial memory users.
\end{abstract}

\section{INTRODUCTION}

The World Wide Web is a highly used hypertext interface on the Internet. Since the beginning of the 1990's, websites have seen permanent growth, with 170 million websites in existence today. ${ }^{1}$ According to research and survey results, the majority of websites are considered difficult to explore, with the majority of the navigational attempts ending in failure [1]. The present study investigates cognitive dimensions that may underlie those difficulties, and design approaches that may help resolve them.

\section{HYPERTEXT STRUCTURE AND NAVIGATION}

The term "hypertext" indicates the principle organization of non-linear electronic documents. Nelson [2] describes hypertexts as components of informational units, or nodes, connected by links in a non-linear way. Hypertexts are stored in computers. Therefore, their pages are accessible through user interfaces. Because the pages appear on the screen only at the time of consultation, in contrast to printed texts, hypertexts presents the particularity of not being visible in their entirety to the user.

Hypertext presents several paths between the nodes, allowing for the personalization of the way documents are consulted. As each node may be connected to several other nodes, unlike single linear texts, hypertext nodes do not always follow each other in a unique, coherent order during navigation. Some hypertexts contain a coherent text, such as

*Address correspondence to this author at the Budapest University of Technology and Economics (BME), Hungary;

E-mail: voroszsofia@gmail.com

\footnotetext{
${ }^{1}$ See http://www.metamend.com/internet-growth.html.
}

electronic encyclopedia, books or scientific publications, but most of them contain information, not strictly coherent, divided into nodes understandable separately, like newspapers, personal or touristic sites. Thus, in most cases, the formal architecture of hypertext is not determined by the semantic structure of the nodes and vice versa. Therefore, knowing the semantic structure of the content is not sufficient to navigate efficiently. Even in cases where the semantic structure affects the formal structure, the lack of knowledge on the topic can prevent users from perceiving it [3].

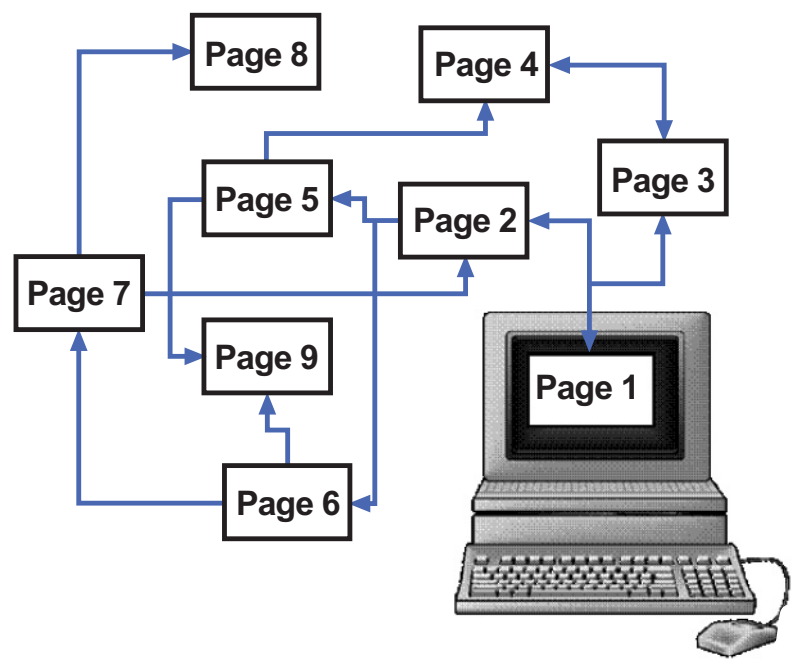

Fig. (1). Schematic representation of the hypertext network, of which users have only a partial representation.

For these reasons, the structure of hypertext can be defined on two levels: the informational content level, which 
represents the semantic space, and the layout level, which defines a topological space $[4,5]$. Understanding the global structure of hypertext requires the user to identify both the semantic and topological components, which do not always overlap.

Hypertext researchers have investigated the cognitive processes that underlie hypertext navigation and learning. For Van Hooijdonk, Maes, and Ummelen [6], hypertext users face three tasks, which can result in three different layers of mental representations:

- A pragmatic layer, representing the planning and execution of the task;

- A semantic layer, representing the informational content to be read;

- A perceptual layer, representing the navigation experience in terms of time and space.

Hypertext structure and content can be comprehended by passing from one node to another in their partially visible virtual network. Therefore, navigation involves the tasks relating to the understanding of semantic information and those in connection with route search activity in space. In addition, navigation is achieved by manipulating computer peripherals (keyboard, mouse), which still adds supplementary treatments compared to reading a book.

More levels of processing imply that hypertext navigation results in a greater cognitive load than reading a printed text. The existing literature suggests that disorientation and cognitive overload are the most fundamental difficulties that users undergo during the navigation [4, 7-10]. Cognitive overload is linked to the quantity of tasks to be solved at the same time. Paas, Renkl and Sweller [11] identified several sources of cognitive load during learning. The extrinsic load does not depend on the content, but it is due to how the information is presented. Thus, the presentation of semantic content as hypertexts can lead to a higher cognitive load than its printed versions. As the low level organization (words, letters, sentences) of hypertexts and printed texts is the same, the two types of text can be opposed in how the user accesses information from one node to another [12].

It is worth noting that disorientation is a metaphorical term for navigational problems concerning orientation in hypertext spaces. More specifically, Elm and Woods [13] identified three types of disorientation:

- $\quad$ Not knowing the location of the target item, i.e. where to go.

- Knowing the positioning of the target item, but not knowing how to get there.

- Not knowing the location of the page consulted in the document.

A specific issue is to find out whether the perceptual and semantic layers involved in hypertext navigation call upon specific and possibly distinct processes. Navigation within networks of pages and links has been compared to the exploration of a new physical environment, leading hypertext theorists to assume the involvement of a spatial or quasi-spatial component in hypertext learning. More precisely, hypertext navigation involves both moving from one point to another and learning the structure of the informational space [5]. Both components are expected to be facilitated by spatial representation skill.

\section{WAYFINDING AND ORIENTATION IN PHYSICAL SPACE AND HYPERTEXT}

In order to be able to orientate in hypertext, users need to know where they are in the structure and how they got there. They need to know the possible paths and be able to produce a path to the target node where they can find the required information $[4,8]$. These tasks of hypertext navigation match those of finding a path in a physical environment, as defined by Downs and Stea [14]:

- Defining the person's location and the target location;

- Choosing the correct route, i.e., the paths that connect the points of departure and arrival;

- Monitoring the chosen route: constantly control, assess and confirm the chosen path;

- Recognize that the destination has been reached.

How do we find our way when moving from one place to another? Navigation in a physical environment has two components: a cognitive process in order to plan the movements, and the actual locomotion. In general, it is not possible to see or to remember the experienced environment in its entirety. Planning and execution of moves are only possible thanks to a mental representation of the environment. In other words, to find one's way in a largescale environment, one needs to keep track of the perceived space. Formal representations, descriptions or maps $[15,16]$, and mental representations of the environment enable us to plan actions taken in order to accomplish our wayfinding tasks $[17,18]$. According to Siegel and White's [18] classical theory, spatial representations are elaborated gradually during navigation. First, important elements of the environment - the landmarks- are identified. In the next step landmarks are connected - this is route knowledge. Route knowledge describes temporally ordered sequences of actions carried out during navigation to reach target places [19]. In the last step, the person organizes the whole into a survey representation of the environment in order to produce the cognitive map of the environment. Mental maps are acquired via the repeated exploration of the environment by using several routes. Even though mental maps do not exactly mimic the real world, they are organized around landmarks in a hierarchical fashion [20], containing directional [21] and distance [22, 23] distortions, defining finally a topological space [24]. Hypertext structure also defines a virtual topological space whose elements correspond to the requirements of those of spatial representations [25]. Nodes can contain various objects and can function as landmarks. Links can be used as roads. Links and nodes can be characterized by information describing directions, locations or other attributions.

External maps showing the spatial relationships can lead directly to the development of a survey representation [16]. In addition to maps, spatial descriptions can also be used as a guide to orientate. Although the hypertextual space is a virtual space, where the motor dimension of navigation is replaced by the manipulation of computer peripherals, the 
Internet vocabulary uses many items expressing movements in space - like "jump" from a page to another, "visit" a site, "open" a page - in order to describe navigational activities, and the space in which those activities take place. Recent theories on text comprehension [26, 27] emphasize the perceptual character of the situation or mental models. The original concepts of a situation model [28] and a mental model [29] also support the idea that representations derived from descriptions contain the structure of the described space and in this regard are similar to the representations based on direct visual perception or external map representations [30, 31].

\section{INDIVIDUAL DIFFERENCES IN LEARNING SPATIAL ORGANIZATION}

Studies show that by navigation, some people can get to know the environment on the survey level very quickly, while others can never produce a cognitive map [16, 32]. The potential individual differences that may account for these differences in the quality of spatial mental representations are ones spatial abilities and working memory capacity.

Spatial abilities, like visualization, mental rotation or spatial perception, enable us to code, recall, transform spatial information, and orientate during wayfindings [33]. According to Baddeley [34], working memory (WM) is a limited capacity multicomponent system maintaining and manipulating information during cognitive tasks. WM can be described as a system consisting of two separate stores guided by a central executive. One memory store, the phonological loop (PL), is specialized in phonological information, while the other one, the visuospatial sketchpad (VSS), in visuospatial information. Individual differences in spatial orientation abilities may be partially explained by differences in VSS $[35,36]$ and therefore the comprehension of spatial texts may also depend in part on VSS capacity [37, $38]$.

\section{EMPIRICAL EVIDENCE ON SPATIAL QUALITIES OF HYPERTEXT NAVIGATION}

Up to now, empirical studies of hypertext navigation have failed to demonstrate unambiguously the involvement of spatial cognitive processes. They have, however, provided indirect evidence in that respect. For instance, several experiments have found a positive influence of spatial metaphors on navigation efficiency [5, 39]. Participants navigating in hypertext conceptualized as a space, have memorized more links and built up a more network like mental representation of the layout than participants navigating with book metaphor instructions [39]. It was also observed that by working with hypertexts, users are interpreting their task using spatial metaphors [6, 40]. Edwards and Hardman [41] found benefits of a hierachical organization over alphabetical and mixed conditions, and suggested that hypertext navigation devices mimic spatial representations in order to facilitate learning [see also 42, 43].

Other studies found that visualization ability [44-46] influences navigational performance. High visualization ability facilitates navigation in the sense that high visualization subjects take less time and activate fewer links to explore hypertexts or find specific information than other participants. Pazzaglia, Toso and Cacciamani [47] found that VSS influenced learning the hypertext layout, while PL played a role in the comprehension of semantic content, but they did not find any influence of short term memory capacities.

On the other hand, some empirical studies found that navigation results in a representation of the semantic relations and not that of the formal layout of hypertext [48, see also 49]. By evaluating navigational task descriptions, Eveland and Dunwoody [50] found that users referred to the semantic content, but not to the layout.

The effects of content maps also vary as a function of situational and individual parameters. For instance, McDonald and Stevenson [43] found that graphical overviews are most useful for users with little prior knowledge; Potelle and Rouet [51] demonstrated that hierarchical - but not network maps - facilitated the learning of hypertext for readers with low prior knowledge and that the hierarchical structure is better retained during navigation. Nilsson and Mayer [45] have also demonstrated that participants using a map had not been forced to treat their task deeply, so they developed a research strategy, which has shown little or no improvement over time.

None of these studies, however, have directly investigated the potential interactions of hypertext design options and users' spatial ability.

\section{RATIONALE}

In the present study, we investigated the hypothesis that content maps may be helpful for readers with reduced VSS capacity. They would serve as an adjunct organizer, reducing the cognitive complexity of mentally representing and remembering the link structure of hypertext.

More specifically, we expected that content maps would generally facilitate the encoding of the link structure of hypertext during exploratory navigation. We expected the benefits of content maps to increase with the structural complexity of hypertext, as measured by the number of nodes and links to be remembered. Finally, we predicted that content maps to be especially beneficial to low VSS readers who cannot devote the spatial resources needed to encode and remember link structures while navigating and comprehending the contents of hypertext.

\section{METHOD}

\section{Participants}

Thirty-two volunteers with diverse academic backgrounds (25 females, age range 21-41 years) participated in the experiment as volunteers. All participants were native French speakers. They were tested individually in a single session of up to an hour.

\section{Materials}

Four small hypertexts were created about four different topics (species of flowers, fish, mammals, vegetables). Each hypertext was designed in a short (6-page) and a longer (9page) version. All hypertexts had a purely hierarchical structure created by randomly sorting bi-directional links. In addition, the hypertexts were presented with or without a 


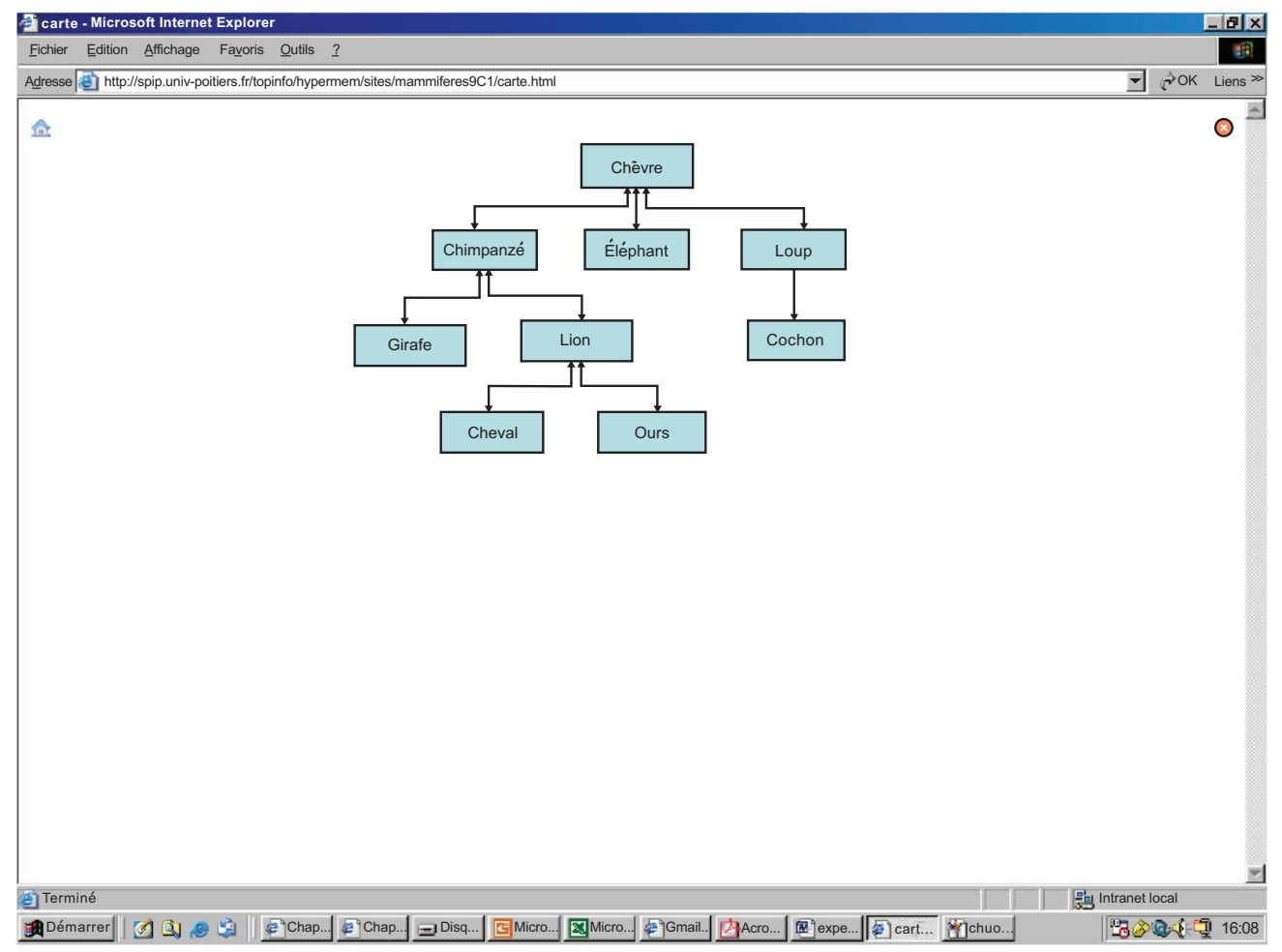

Fig. (2). An example of a structure and an interactive concept map. Nodes are clickable and lead to respective pages.

high-level content map (map or title condition). Thus, there were 16 different hypertexts: 4 Topics X 2 Length (6-page vs 9-page) X Map presence (map vs title condition). The pages were always organized in four hierarchical levels (see Fig. 2).
The opening page of the hypertexts was a blank node with the topic name (e.g., "flowers"; see Fig. 3).

Each other page included the name of a species and a short descriptive sentence, without any reference to other pages. (see Fig. 4). Thus, the link structure could not be

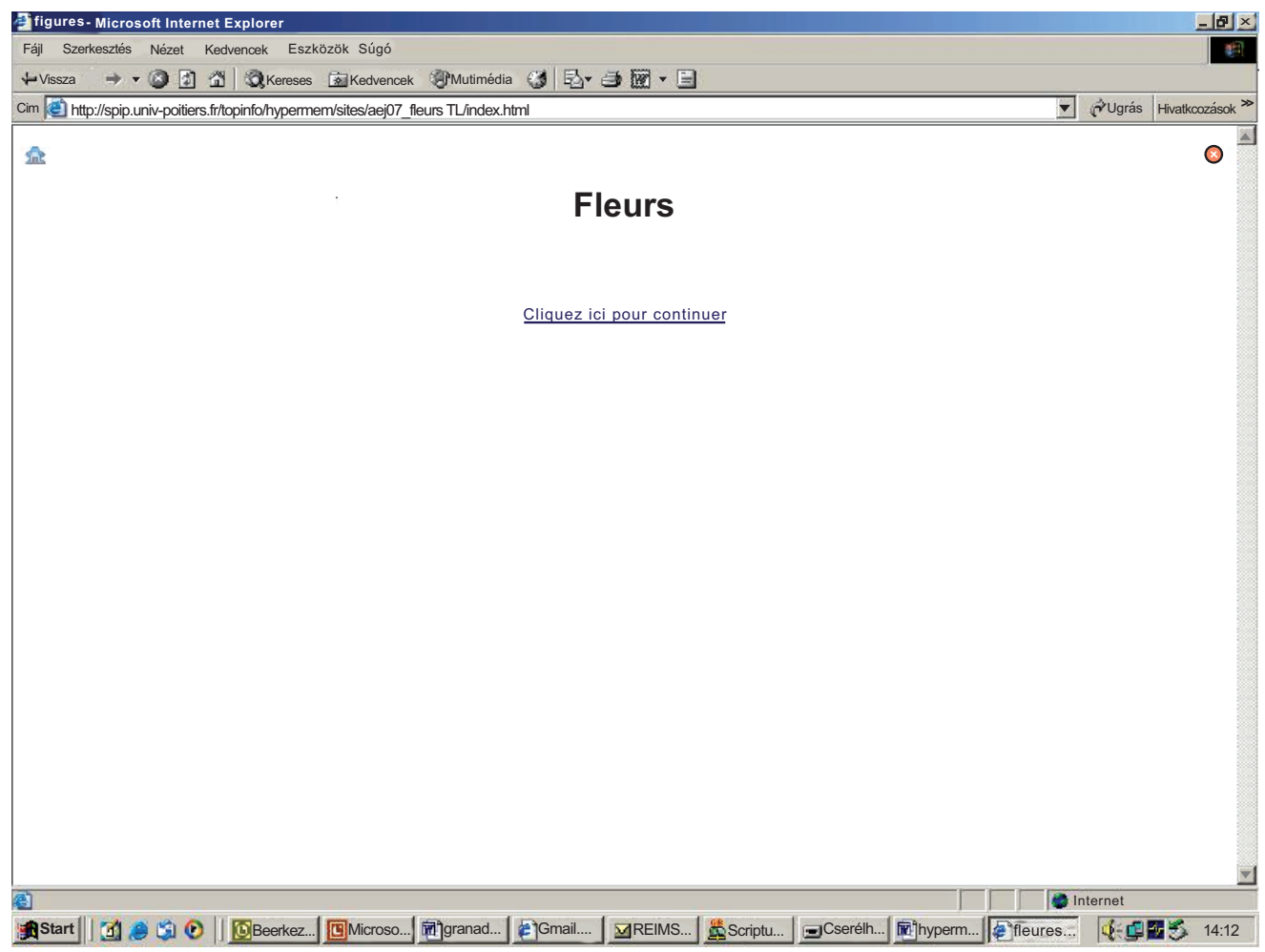

Fig. (3). An example of an opening page. 


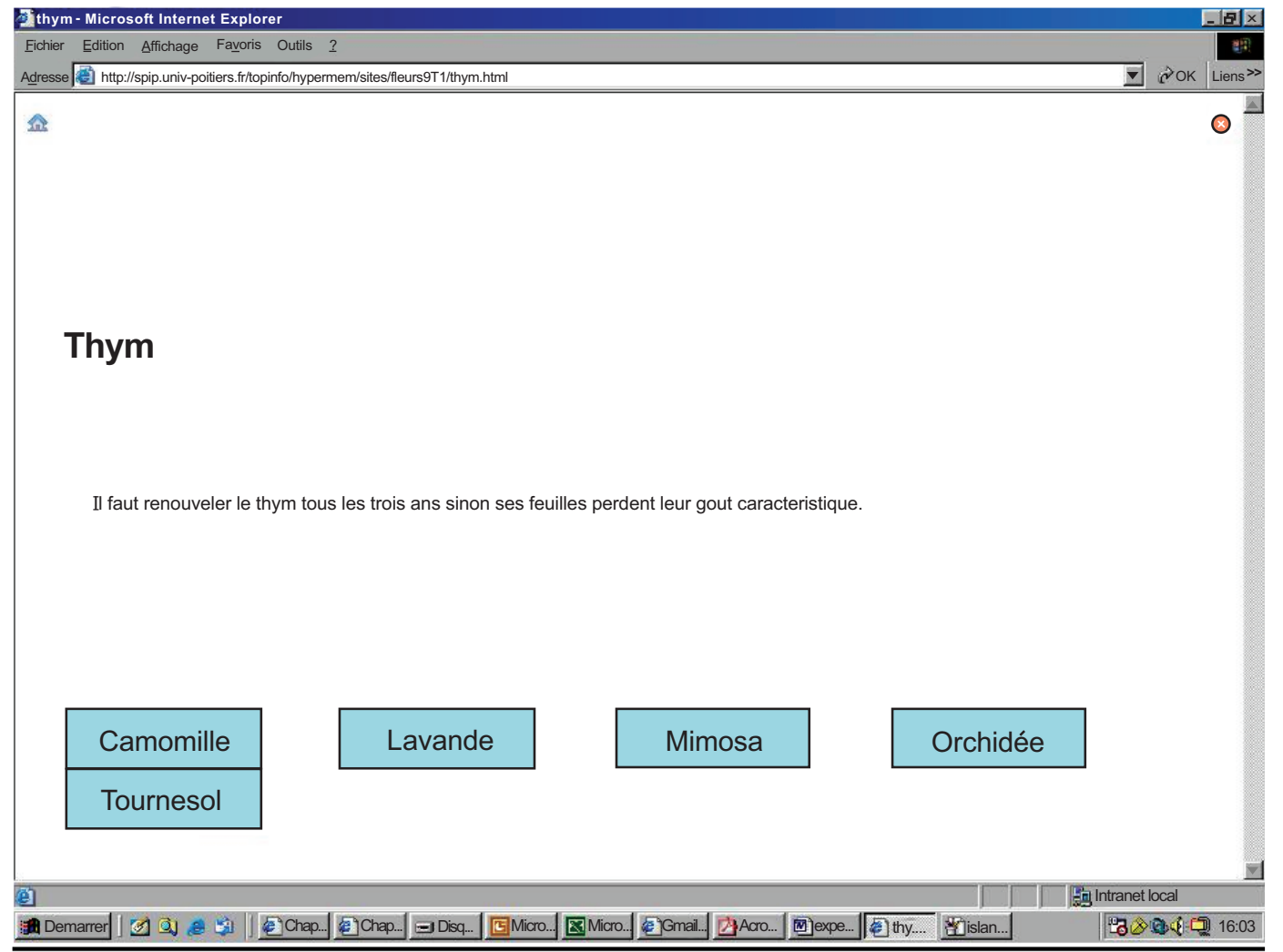

Fig. (4). An example of a page in the "Title" condition. Linked pages are listed in alphabetical order.

inferred from a semantic representation of the content. Links were displayed at the bottom of each page, in alphabetical order, without any cue regarding their respective hierarchical position. Content pages also included a "Home" icon that returned to the opening page. When no map was available ("title" condition), users could navigate by using the links included on each content page, or by returning to the opening page through the "Home" button. Thus, in the title condition no global content representation available and the hypertext structure had to be inferred from navigation.

In the map condition an additional "Map" button was present as the last link on each page. The content map (Fig. 2) was linked to all other pages. Clicking on the name of a species on the map resulted in the display of the respective page.

\section{Procedure}

Participants were asked to navigate four hypertexts with the instruction to remember he contents and the link structure during the open task. The factors of Length of hypertext (6-page vs 9-page) and Map presence (Map condition vs Title condition) were manipulated within subjects. Thus, participants received each topic in one of the 4 conditions. The maximum time for navigation of a hypertext was three minutes, but the participants were free to stop navigation before if they considered that they had finished their task.

Half of the participants first navigated in two hypertexts with a content map, while the other half of the participants began with the "no map" (i.e., title) condition. The two navigation conditions were separated by a spatial memory test (VSS). A computerized version of a Corsi Blocs-like test, applied by Pickering, Gathercole, Hall and Lloyd [52] was used to measure the participants' VSS capacity. The participants had to retain and repeat on a touch-screen the order of appearance of black boxes on a matrix. Participants were categorized as high or low span based on their performance on this task.

After completing each hypertext, the participants were asked to draw a map of the pages and links using a list of species names as recall cues. One third of the species mentioned in the list were distracters. Participants had to draw arrows in order to represent the links between the pages (Fig. 5).

Finally, the participants were provided with a list of nodes titles (eg, "goat") and a list of content words taken from the page contents (eg, "bell"). They had to draw arrows between titles and respective content words, as a measure of their memory for the semantic contents of the pages.

\section{RESULTS}

Following the literature on spatial cognition, we evaluated spatial knowledge at the landmark and route levels. As the hypertexts were very simple and only one link was used to indicate each page, route knowledge also determined the survey knowledge. Consequently, survey knowledge was not assessed separately. Landmark knowledge was measured by the percentage of species 


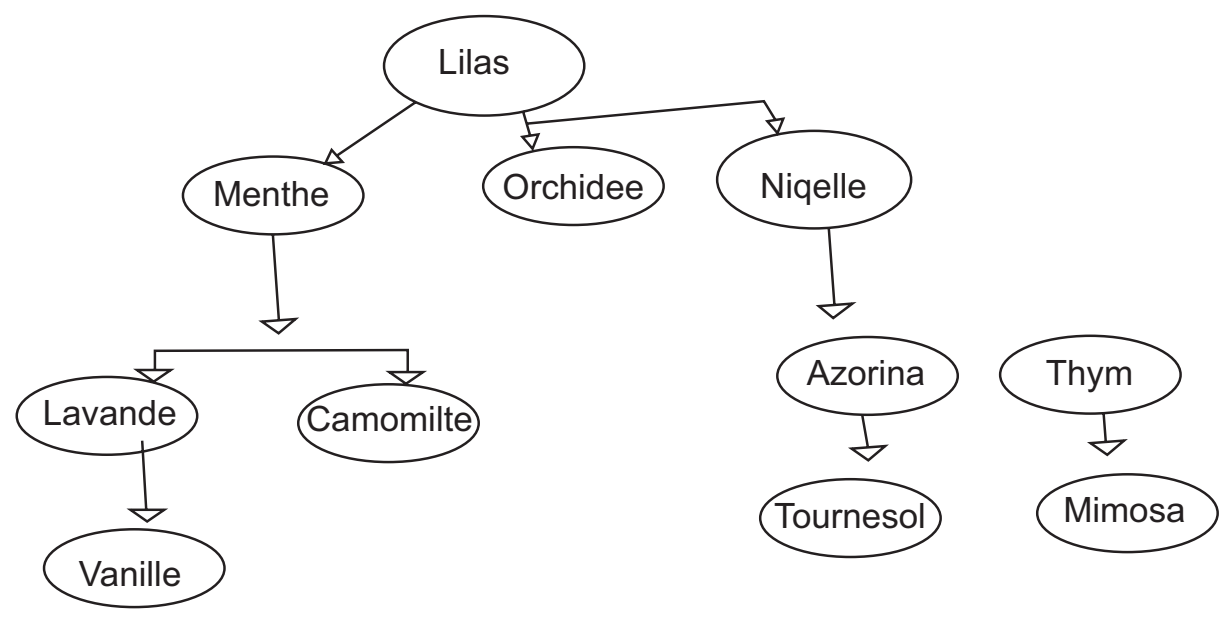

Fig. (5). An example of a map drawing.

names correctly identified. Route knowledge was characterized by the proportion of correct links. The metrics were the averages of the number of correctly recalled titles or links over the total number of titles or links drawn and over those numbers in the original layout. The metrics used gave a result between 0 (poor representation) and 1 (totally accurate representation).

\section{Landmark Knowledge}

The recall of page titles (i.e., landmark knowledge), was almost perfect in all four conditions (Fig. 7, left). The Wilcoxon sign-rank test found no effect of Map presence on landmark knowledge $(\mathrm{Z}=1.682, \mathrm{n}=32, \mathrm{p}=0.093)$. There was also no main effect of visuo-spatial ability and no interaction.

\section{Route Knowledge}

The recall of links (i.e., route knowledge) varied as a function of the structural complexity and the presence or absence of a map (Fig. 6, right). In the case of 6-page hypertexts, in the title condition $56.3 \%$ of the subjects retained perfectly the structure and this percentage was $84.4 \%$ in the map condition. The increase of the number of pages made the development of the mental representation of the structure more difficult.
Due to the high number of totally accurate representations and heterogeneous variances across conditions, the results were analyzed using non parametric statistics. The Wilcoxon sign-rank test showed a significant effect of length for both the Title $(\mathrm{Z}=2.841, \mathrm{n}=32, \mathrm{p}=0.005)$ and the Map condition $(\mathrm{Z}=2.841, \mathrm{n}=32, \mathrm{p}=0.025)$. The structure of 9-page hypertexts was more difficult to learn than that of 6-page hypertexts. Because of ceiling effects in the 6-page condition, the effects of content maps and VSS capacity were analyzed only for 9-page hypertexts. The Wilcoxon sign-rank test found a significant effect of Map presence on route knowledge $(Z=2.610, n=32, p=0.009)$ but not on landmark knowledge $(Z=1.682, n=32, p=0.093)$.

The Map by capacity interaction was examined by comparing the two extreme subgroups of participants on the VSS capacity scale: the 8 participants with the lowest scores on the corsi-bloc task $v s$ the 9 participants with the highest scores. Mann-Whitney U tests were conducted on the 9-page hypertexts to determine whether VSS capacity influenced route knowledge (see Fig. 7).

For Route knowledge, there were spatial capacity differences in the Title condition. In this condition, participants with a high VSS capacity recalled more route level knowledge than participants with low VSS capacity $(\mathrm{U}=11,00, Z=-2,41$, exact $\mathrm{p}=0,015)$ The difference between

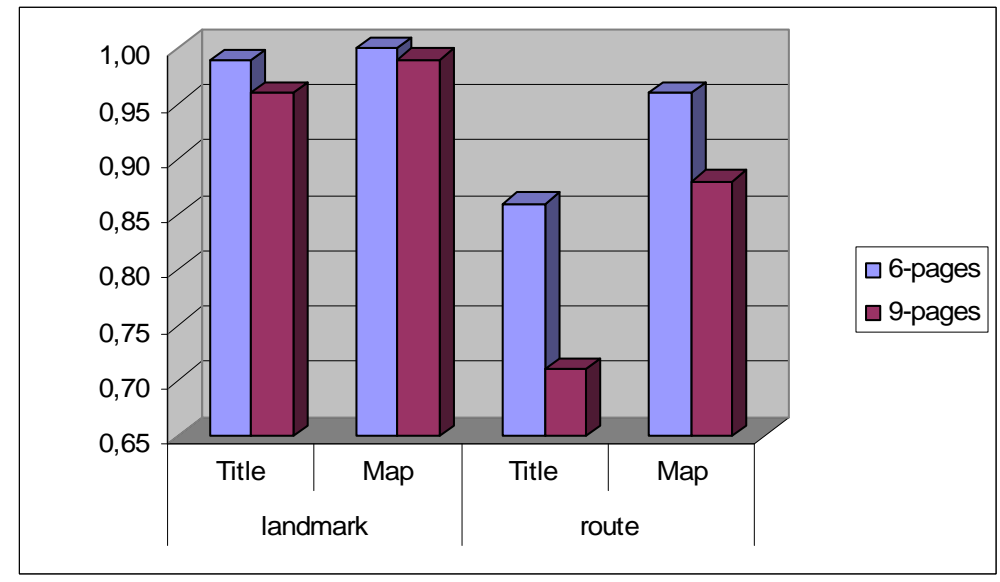

Fig. (6). Landmark and route knowledge as a function of hypertext length (6 vs 9 pages) and map condition. (NB. performance was measured on a standardized scale between 0 to 1$)$. 


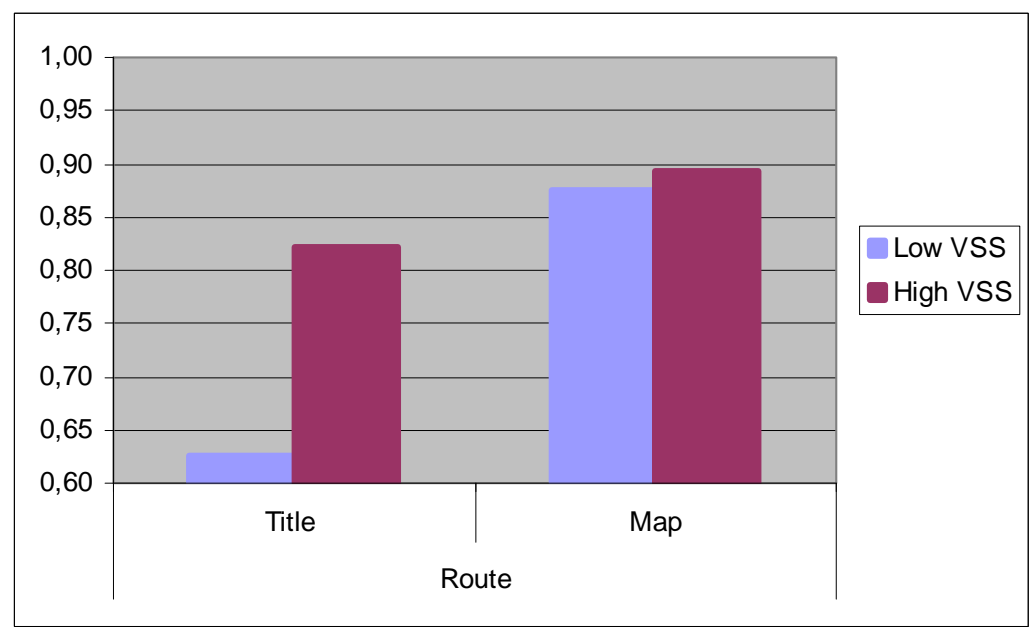

Fig. (7). Page and link recall of 9-page hypertext as a function of VSS span and map condition.

low and high memory participants disappeared almost completely in the presence of the map $(U=35,00, Z=-0,10$, exact $\mathrm{p}=0,963)$. The result was fully consistent with our prediction that high-level content representations would act as scaffolds, especially for low spatial capacity hypertext users.

\section{Use of Navigational Aid}

We also analyzed the use of the map vs home page during navigation (see Fig. 8). The sign test showed that the number of returns to the home page was significantly higher in the title condition than in the map condition both in 9page $(Z=2,412, p=.016)$ and in 6-page hypertexts $(Z=$ $2,219, p=.027)$. In the map condition, both for 9-page $(Z=$ $5.48, \mathrm{p}=.000)$ and 6-page $(Z=5.48, \mathrm{p}=.000)$ hypertexts, participants chose the map significantly more often than the opening page. A one-way ANOVA showed that the participants visited the map for more frequently while navigating in 9-pages hypertexts that in 6-pages hypertexts, $\mathrm{F}(1,30)=4,482, \mathrm{p}=.043$.

\section{Content Comprehension}

We could not find any effect of the length and presence of the map on our simple measure of content comprehension. Performance was high with and average of $73 \%$ of correct responses.

\section{DISCUSSION AND CONCLUSION}

The objective of this experiment was to demonstrate that high level content maps facilitates the learning of hypertext structure and supports navigation, especially for low spatial memory users. We asked participants with low and high spatial memory capacity to explore short and longer hypertexts, with or without content maps, with the instructions to remember the contents and the structure of pages. The hypertexts had no predictable inter-page semantic structure and pages were linked randomly though hierarchically. The results were generally in favor of our predictions.

The small size of the hypertexts used in this experiment made it easy for all participants to remember the titles of the

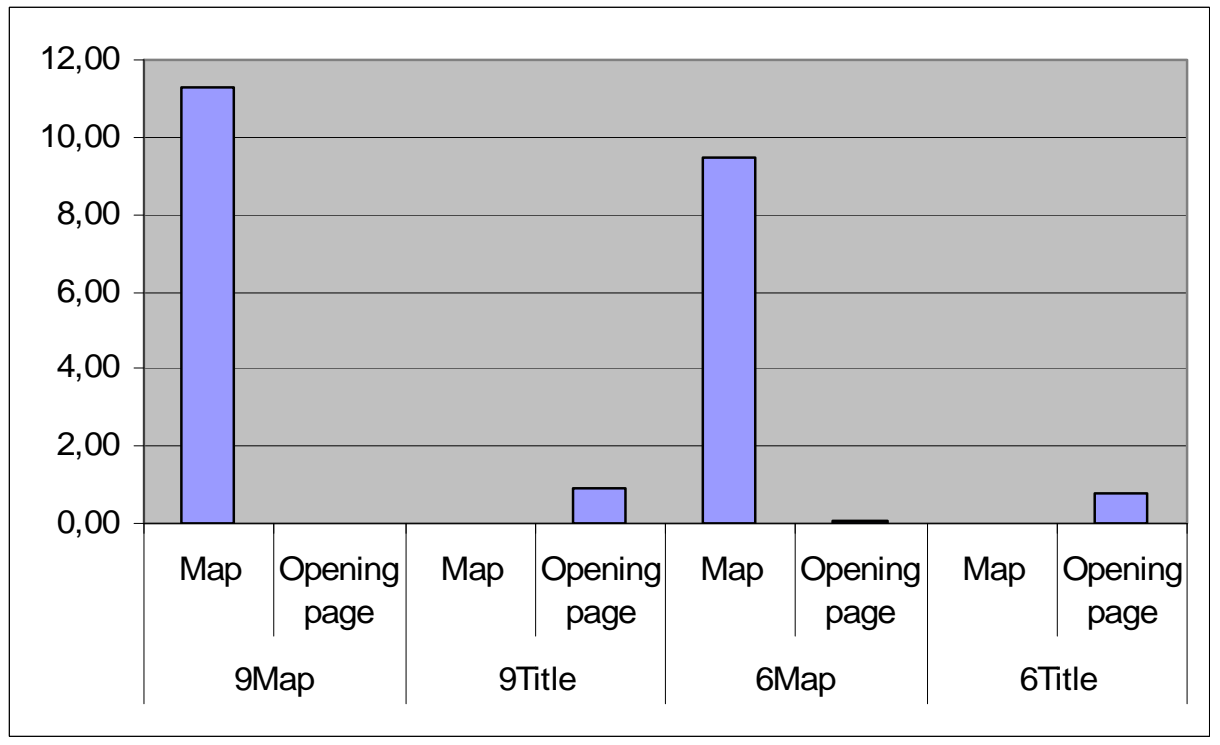

Fig. (8). Average use of map and opening page during hypertext exploration. 
pages they had visited, regardless of hypertext size and presentation condition (map vs no map). The construction of a "route" kind of memory trace was, however, harder to achieve. In the title condition, a high spatial memory capacity was needed to build route knowledge of the link structure on the basis of the succession of screens viewed while navigating. The increase in the number of pages and links made the construction of the route representations more difficult. The content map seemed to act as an external visuo-spatial memory, facilitating the development of the route knowledge of a hypertext structure. The map was efficient enough to eliminate the difference between low and high spatial memory participants. Without a map, spatial memory capacity influenced the quality of structural recall, but when the map was available its effect disappeared.

The participants had to return to the opening page or to the map to support their orientation while navigating. Participants preferred to use the map, when it was present, than the opening page for orientation purposes. The map was used more often when the structure was more complicated. When no map was available, returning to the home page was sometimes used as an alternative, as in earlier studies [53].

Our results are consistent with theories of spatial cognition $[18,36]$ and confirm our assumptions as regards hypertext navigation. Navigating hypertext involves spatial processes similar to those needed to learn physical environment [5, 44, 47]. External content representations reduce the amount of processing needed to build up a mental representation of the hypertext layout, thus helping users with a low visuo-spatial sketchpad capacity.

How spatial processes relate to the comprehension of the hypertext semantics remains to be investigated. Indeed, from the point of view of the user, hypertext is above all a semantic space. One can thus suppose that semantic relationships also influence the structural representation and the navigational decisions. It would be interesting to further investigate the interactions between spatial and semantic structures, spatial abilities, navigational patterns and their influence on comprehension and navigation efficiency.

\section{ACKNOWLEDGEMENT}

The research presented here was supported in part by a grant from the French Ministry of Foreign affairs to the first author. We thank Mary Anne Britt for her help in revising and editing the final version of the paper.

\section{REFERENCES}

[1] Nielsen J. Designing Web Usability: The Practice of Simplicity, $3^{\text {rd }}$ ed. Indianapolis: New Riders Publishing 2000.

[2] Nelson TH. Complex information processing: a file structure for the complex, the changing and the indeterminate. In: Proceedings of the $20^{\text {th }}$ ACM National Conference. New York: ACM Press 1965; pp. 84-100.

[3] Rezende F, Barros S. Students' navigation patterns in the interaction with a mechanics hypermedia program. Comput Educ 2008; 50: 1370-82.

[4] Kim H, Hirtle SC. Spatial metaphors and disorientation in hypertext browsing. Behav Inform Technol 1995; 4: 239-50.

[5] Padovani S, Lansdale M. Balancing search and retrieval in hypertext: context-specific trade-offs in navigational tool use. Int $\mathrm{J}$ Hum Comput Stud 2003; 58: 125-49.

[6] Van Hooijdonk C, Maes A, Ummelen N. «I have been here before " An investigation into spatial verbalisations in hypertext navigation. Inf Des J 2006; 14(1): 8-21.
[7] Chen YS, Fan JP, Macredie DR. Navigation in hypermedia learning systems: experts vs Novices. Comput Hum Behav 2006; 22: 251-66.

[8] Conklin J. Hypertext: an introduction and Survey. IEEE Comput 1987; 20: 17-41.

[9] Dillon A. Spatial-Semantics. How users derive shape from information space. J Am Soc Inform Sci 2000; 51(6): 521-8.

[10] Rouet JF, Potelle H. Navigational principles. In: Mayer RK, Ed. Cambridge Handbook of Multimedia Learning. Cambridge, MA: Cambridge University Press 2005; pp. 297-312.

[11] Paas F, Renkl A, Sweller J. Cognitive load theory and instructional design: recent developments. Educ Psychol 2003; 38: 1-4.

[12] Esperet E. Notes on hypertext, cognition, and language. In: Rouet JF, Levonen JJ, Dillon A, R. Spiro RJ, Eds. Hypertext and Cognition. Mahwah, NJ: Lawrence Erlbaum 1996; pp. 149-55.

[13] Elm W, Woods D. Getting lost: A case study in interface design In: Proceedings of the Human Factors Society 29th Annual Meeting. Santa Monica, CA: Human Factors Society 1985; pp. 927-31.

[14] Downs RM, Stea D. Cognitive maps and spatial behavior: Process and product. In: Downs RM, Stea D, Eds. Image and Environment. London: Edward Arnold 1973; pp. 8-26.

[15] Taylor HA, Tversky B. Spatial mental models derived from survey and route descriptions. J Mem Lang 1992; 31(2): 261-92.

[16] Thorndyke PW, Hayes-Roth B. Differences in spatial knowledge acquired from maps and navigation. Cogn Psychol 1982; 14: 56089.

[17] Ekstrom AD, Kahana MJ, Caplan JB, et al. Cellular networks underlying human spatial navigation. Nature 2003; 425: 184-7.

[18] Siegel AW, White SH. The development of spatial representations of large-scale environments. In: Reese HW, Ed. Advances in child development and behavior. New York, NY: Academic Press 1975; pp. 9-55.

[19] Golledge RG. Human wayfinding and cognitive maps. In Golledge RG, Ed. Wayfinding Behavior: Cognitive Mapping and Other Spatial Processes. Baltimore, MD: The Johns Hopkins University Press 1999; pp. 5-45.

[20] McNamara TP, Hardy JK, Hirtle SC. Subjective hierarchies in spatial memory. J Exp Psychol Learn 1989; 15(2): 211-27.

[21] Tversky B. What do Sketches say about Thinking? 2002 [Retrieved 2007 December 5]. Available from: http://www-psych.stanford. edu/ bt/diagrams/papers/sketchingaaai02format.doc.pdf

[22] Landau B, Jackendoff R. "What" and "where" in spatial language and spatial cognition. Behav Brain Sci 1993; 16: 217-65.

[23] McNamara TP, Diwadkar VA. Symmetry and asymmetry of human spatial memory. Cogn Psychol 1997; 34(2): 160-90.

[24] Hirtle SC, Heidorn BP. The structure of cognitive maps. Representations and process. In: Garling T, Golledge RG, Eds. Behaviour and environment. Psychological and Geographical Approaches. Amsterdam: North-Holland 1993; pp. 170-92.

[25] Shum S. Real and virtual spaces: mapping from spatial cognition to hypertext. Hypermedia 1990; 2(2): 133-58.

[26] Barsalou LW. Perceptual symbol systems. Behav Brain Sci 1999; 22(4): 577-660.

[27] Glenberg AM, Robertson DA. Indexical understanding of instructions. Discourse Process 1999; 28(1): 1-26.

[28] van Dijk TA, Kintsch W. Strategies of discourse comprehension. $1^{\text {st }}$ ed. San Diego, CA: Academic Press 1983.

[29] Johnson-Laird PN. Mental models: Towards a cognitive science of language, inference, and consciousness. $1^{\text {st }}$ ed. Cambridge, MA: Harvard University Press 1983.

[30] Avraamides MN, Loomis JM, Klatzky RL, Golledge RG. Functional equivalence of spatial representations derived from vision and language: evidence from allocentric judgments. J Exp Psychol Learn 2004; 30: 801-14.

[31] Brunyé TT, Taylor HA. Extended experience benefits spatial mental model development with route but not survey descriptions. Acta Psychol 2008; 127: 340-54.

[32] Ishikawa T, Montello RD. Spatial knowledge acquisition from direct experience in the environment: individual differences in the development of metric knowledge and the integration of separately learned places. Cogn Psychol 2006; 52: 93-129.

[33] Carroll JB. Human cognitive abilities. A survey of factor analytic studies. Cambridge: Cambridge University Press 1993.

[34] Baddeley AD. Working Memory. $1^{\text {st }}$ ed. Oxford: Clarendon Press 1986. 
[35] Garden S, Cornoldi C, Logie RH. Visuo-spatial working memory in navigation. Appl Cogn Psychol 2002; 16:35-50.

[36] Miyake A, Friedman PN, Rettinger AD, Shah P, Hegarty M. How are visuospatial working memory, executive functioning, and spatial abilities related? a latent-variable analysis. J Exp Psychol Gen 2001; 130(4): 621-40.

[37] De Beni R, Pazzaglia F, Gyselinck V, Meneghetti C. Visuospatial working memory and mental representation of spatial descriptions. Eur J Cogn Psychol 2005; 17(1): 77-95.

[38] Pazzaglia F, Cornoldi C. The role of distinct components of visuospatial working memory in the processing of texts. Memory 1999; 7: 19-41.

[39] Bromme R, Stahl E. Is a hypertext a book or a space? The impact of different introductory metaphors on hypertext construction. Comput Educ 2005; 44 (2): 115-33.

[40] Maglio PP, Matlock T. The conceptual structure of information space. In: Höök K, Benyon D, Munro AJ, Eds. Designing information spaces: the social navigation approach. London: Springer 2003; pp. 385-404.

[41] Edwards DM, Hardman L. Lost in hyperspace: cognitive mapping and navigation in a hypertext environment. In: McAleese R, Ed. Hypertext: Theory into practice. Oxford: Intellect Limited 1989; pp. 105-25.

[42] Dee-Lucas D, Larkin JH. Learning from electronic texts: effects of interactive overviews for information access. Cognit Instruct 1995; 13(3): 431-68.

[43] McDonald S, Stevenson RJ. Navigation in hyperspace: An evaluation of the effects of navigational tools and subject matter expertise on browsing and information retrieval in hypertext. Interact Comput 1998; 10(2): 129-42.
[44] Downing ER, Moore LJ, Brown WS. The effects and interaction of spatial visualization and domain expertise on information seeking. Comput Hum Behav 2005; 21: 195-209.

[45] Nilsson RM, Mayer RE. The effects of graphical organizers giving cues to the structure of a hypertext document on users' navigation strategies and performance. Int J Hum-Comput St 2002; 57: 1-26.

[46] Zhang H, Salvendy G. The implication of visualization ability and structure preview design for web information search tasks. Int $\mathrm{J}$ Hum-Comput Int 2001; 13(1): 75-9.

[47] Pazzaglia F, Toso C, Cacciamani S. The specific involvment of verbal and visuospatial working memory in hypermedia learning. Br J Educ Technol 2008; 39(1): 110-24.

[48] Farris JS, Jones SK, Elgin DP. User's schemata of hypermedia: what is so "spatial" about a website? Interact Comput 2002; 5: 487502 .

[49] Stanton N, Correira AP, Dias P. Efficacy of a map on search, orientation and access behavior in a hypermedia system. Comput Educ 2000; 35: 263-79.

[50] Eveland WP, Dunwoody S. Examining information processing on the World Wide Web using think-aloud protocols. Media Psychol 2000; 2: 219-44.

[51] Potelle H, Rouet JF. Effects of content representation and readers' prior knowledge on the comprehension of hypertext. Int J HumComput St 2003; 58: 327-45.

[52] Pickering SJ, Gathercole SE, Hall M. Lloyd SA. Development of memory for pattern and path: further evidence for the fractionation of visuo-spatial working memory. Q J Exp Psychol 2001; 54: 397420.

[53] Britt MA, Rouet JF, Perfetti CA. Using hypertext to study and reason about historical evidence. In: Rouet JF, Levonen JJ, Dillon AP, Spiro RJ, Eds. Hypertext and Cognition. Mahwah, NJ: Lawrence Erlbaum Associates 1996; pp. 43-72.

(C) Vörös et al.; Licensee Bentham Open.

This is an open access article licensed under the terms of the Creative Commons Attribution Non-Commercial License (http: //creativecommons.org/licenses/by$\mathrm{nc} / 3.0 /$ ) which permits unrestricted, non-commercial use, distribution and reproduction in any medium, provided the work is properly cited. 